\title{
A Double Wye Ungrounded Fuseless Shunt Capacitor Bank Protection and Control Overview in A High Voltage Substation using an IED
}

\author{
Mahmoud Said M. Bedeir A. \\ Electrical Power and Machines Department \\ Cairo University \\ Giza, Egypt
}

\begin{abstract}
This paper gives a brief overview on the common shunt capacitor banks (SCB) arrangements. Exploring both fuse and grounding classifications, merits and drawbacks of each type. A case study modeled by PSIM software to demonstrate the overvoltage as a result of capacitor unit loss. The optimum different current and voltage protections applied to the bank during the commissioning stage by use of modern Intelligent Electronic Devices (IED) type of SEL-487V. MVAR and voltage dependent automatic capacitor control switching system (ACCS) logic conditions applied to a three bus bar sectionalized medium voltage switchgear by use of IED controllers. The local control cubicle (LCC) and the schematic controlling the capacitor circuit breaker and earth switch operations and trapped charges discharging interlock.
\end{abstract}

Keywords-Banks, Capacitor, Control, Protection, SCB.

\section{INTRODUCTION}

Shunt capacitor banks (SCB) are a very important power system components which are widely used in transmission and distribution networks to provide a capacitive reactive power compensation. It is normally located near to load centers to increase the power factor, improve system capacity, increase lifetime of the used conductors and enhance the load voltage level as shown in Fig.1.

As shown in Fig.2, A capacitor unit is the building block of any SCB. The capacitor unit consists of individual capacitor elements, arranged in parallel and series connected groups, within a steel enclosure case. The internal discharge device is a resistor that reduces the unit residual voltage allowing switching the bank back after switching it off the service.

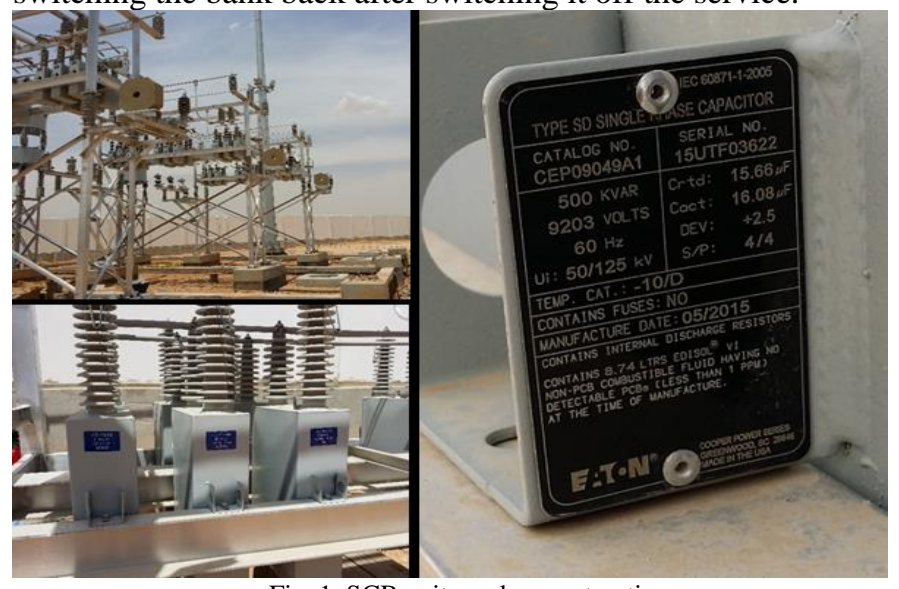

Fig. 1. SCB units under construction

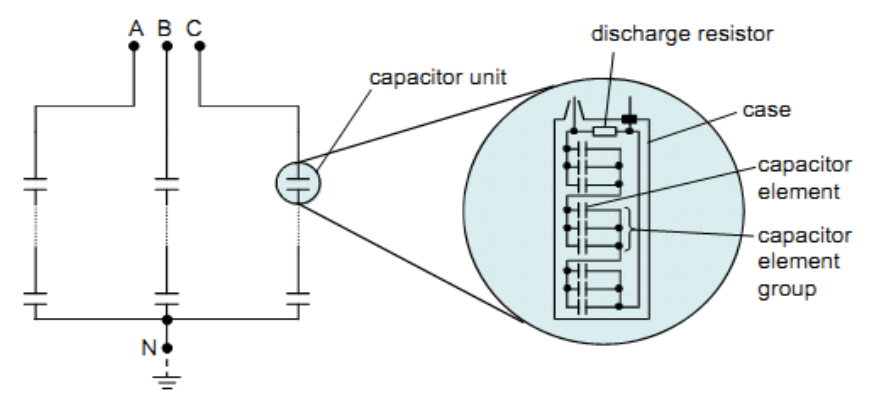

Fig. 2. SCB components

\section{SCB COMMON ARRANGEMENTS AND}

\section{CONFIGURATION}

There are two classifications of SCB arrangements, according to fuses and grounding point of views.

\section{A. SCB classification from fuses point of view}

\section{Externally fused SCB}

In this type a separate fuse placed externally between the capacitor unit and the capacitor bank termination bus to protect each capacitor unit as shown in Fig.3. The main merit of this type is the ease of failure troubleshooting as the fuse can be noticed visually while the main drawback is difficulty of maintenance as the fuse is exposed to environment and once the fuse blown up, the entire unit will be open circuit which leads to high difference overvoltage across the healthy units in parallel as shown in Fig.4.

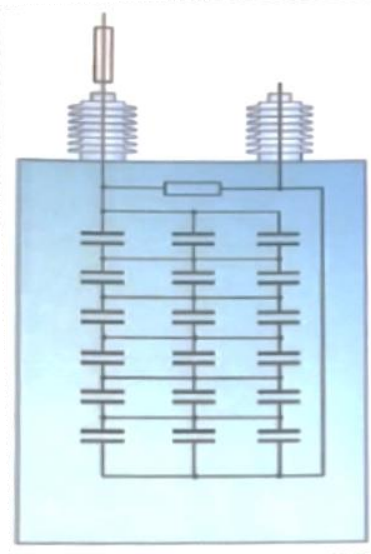

Fig. 3. Externally fused units 


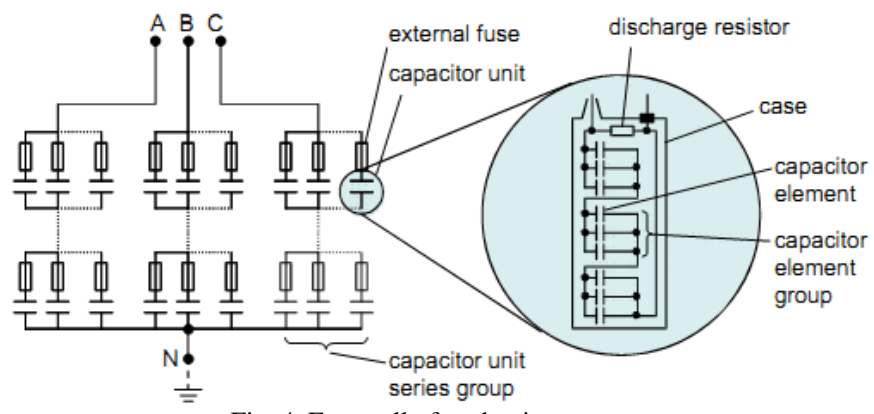

Fig. 4. Externally fused units arrangement

It is noticed that capacitor elements in this type are arranged so that few elements in parallel and many elements in series to minimize the overall unit capacitance so that its value would be comparatively small when the fuse blown up to minimize the overvoltage resulted across the healthy units. Let's explain the overvoltage by an example of 13.8 KV SCB modeled by PSIM as shown in Fig.5, a single phase representation of SCB arrangement before the fuse operation.

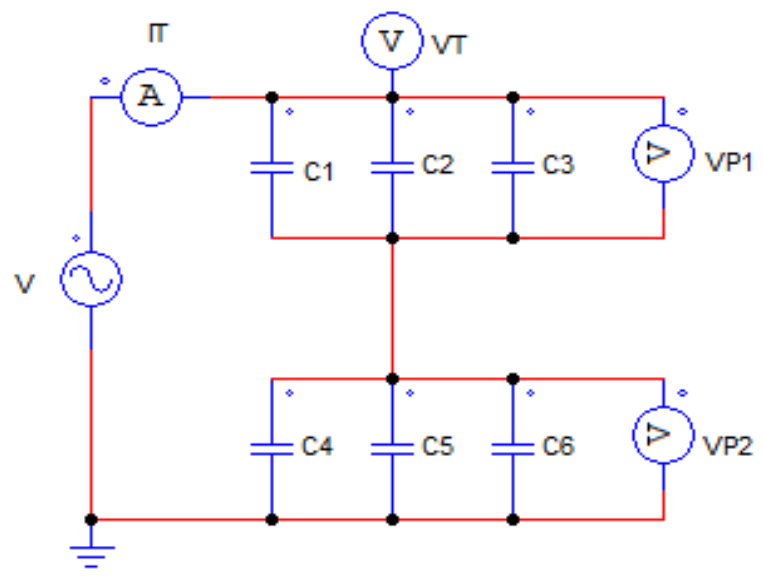

Fig. 5. Representation before fuse operation

The phase voltage will be $7.96 \mathrm{KV}$ and voltage will divided equally between the two parallel groups of value $3.98 \mathrm{KV}$ as shown in Fig.6a and Fig.6b.

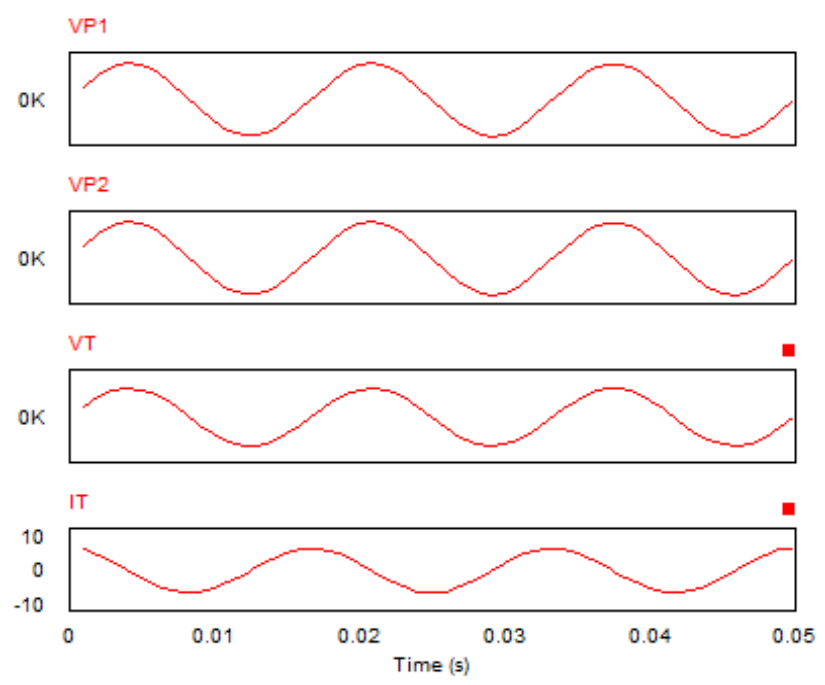

Fig. 6a. Curves of representation before fuse operation

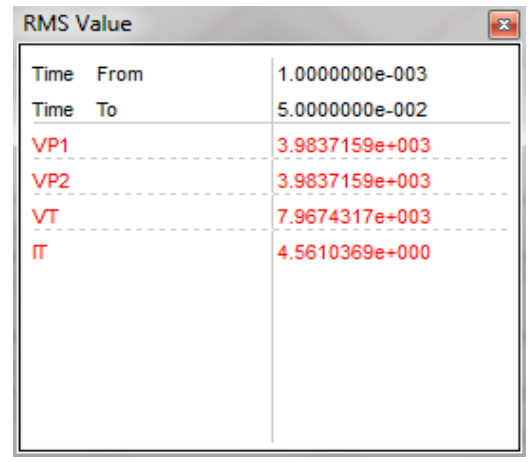

Fig. 6b. RMS value of voltages

After losing $\mathrm{C} 1$ as its fuse is operated due to internal short circuit, an overvoltage of value $4.78 \mathrm{KV}$ (i.e. $120 \%$ overvoltage) will result across the healthy units in parallel as shown in Fig.7.
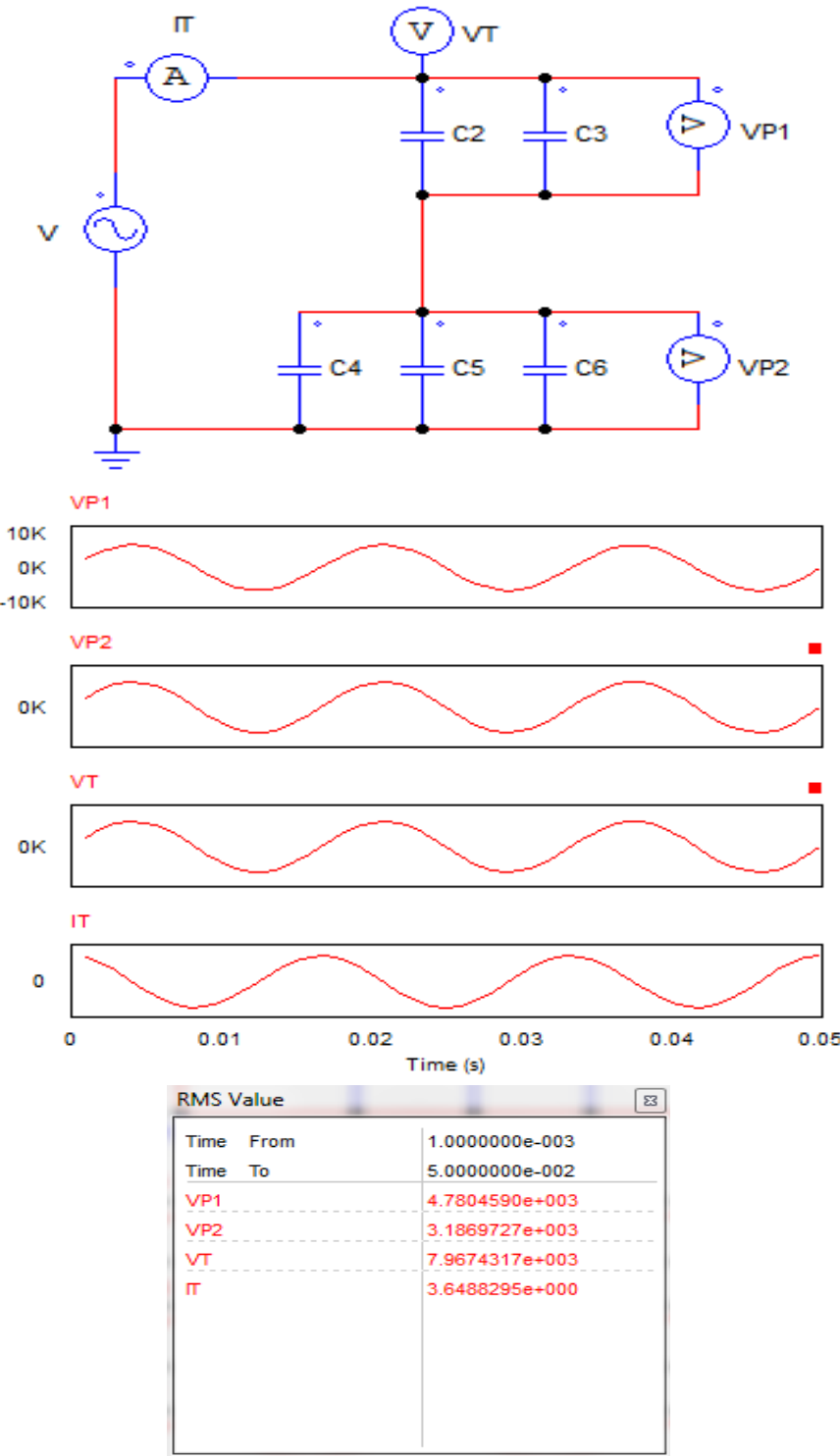

Fig. 7. Curves and RMS voltages of representation after fuse operation

\section{Internally fused $S C B$}

In this type each capacitor element is protected by a separated fuse inside the capacitor unit and once the related capacitor element fails, the fuse removes the affected element 
only as shown in Fig.8. The main merit of this type is minimizing the overvoltage resulted across the healthy units while the main drawback is the higher initial cost as many fuses are to be provided for each unit as shown in Fig.9.

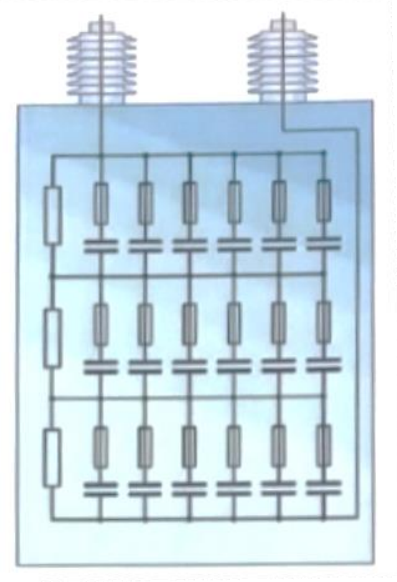

Fig. 8. Internally fused units

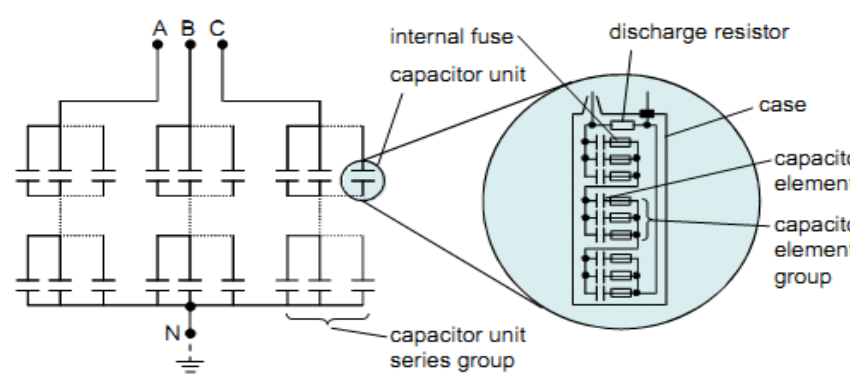

Fig. 9. Internally fused units arrangement

It is noticed that capacitor elements in this type are arranged so that many elements in parallel and few elements in series to maximize the overall unit capacitance as the entire unit will still in service in case of capacitor element failures and fuse operated.

\section{Unfused $S C B$}

This type is similar to the externally fused SCB but without any fuses as shown in Fig.10. The main drawback is once a capacitor unit is short circuited due to failure, the healthy capacitor units in parallel will be useless as soon as shorted.

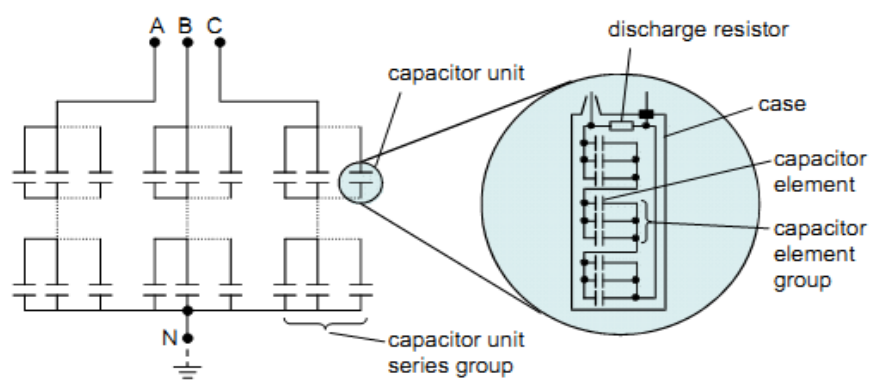

Fig. 10. Unfused units arrangement

\section{Fuseless $S C B$}

This type is the most practical and widely used one where there are no fuses. Capacitor elements are connected in series to build up series strings which connected together in parallel as shown in Fig.11. In case of failure occurred for a capacitor element, it will be short circuited however the remaining elements will still be in service and will not be affected by the failure.

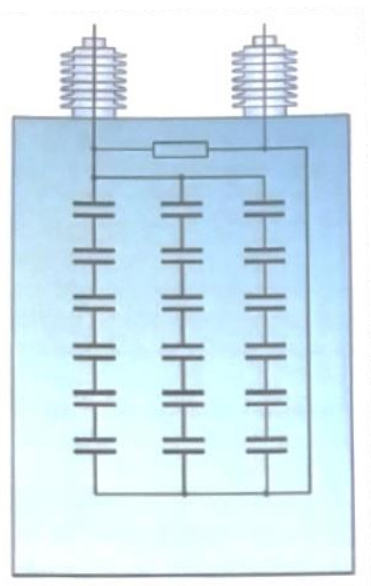

Fig. 11. Fuseless units

\section{B. SCB classification from grounding point of view}

\section{Single wye grounded SCB}

In this type, the SCB units arranged in a single star connection with a grounded neutral as shown in Fig.12. It is usually used in low rating up to 4 MVAR. The grounding here is introducing a low impedance path to ground that used as a natural protection from surge overvoltage and the transient overcurrent.

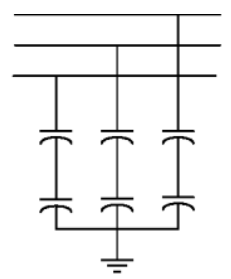

Fig. 12. Single wye grounded SCB

\section{Double wye grounded SCB}

In this type is similar to the single wye but its wye is split into two wyes to produce a high rating more than 7 MVAR and to provide an unbalance protection as shown in Fig.13.

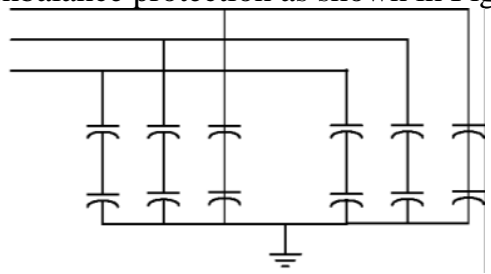

Fig. 13. Double wye grounded SCB

\section{Single wye ungrounded $S C B$}

This type is similar to type (1) but there is no any path to ground i.e. the neutral is isolate as shown in Fig.14. A surge arrestor to be connected to provide a protection from surge overvoltage

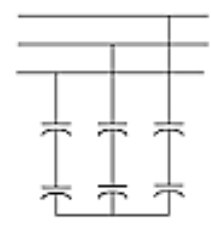

Fig. 14. Single wye ungrounded SCB 
4. Double wye ungrounded SCB

In this type is similar to type (3) but its wye is split into two wyes to produce a high rating as shown in Fig.15. This type is commonly used.

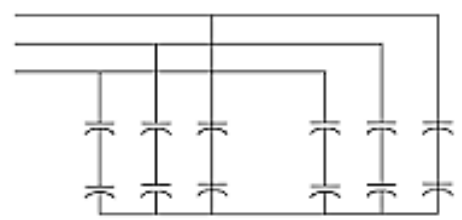

Fig. 15. Double wye ungrounded SCB

\section{PROTECTION OF DOUBLE WYE UNGRONDED SCB}

Different protections are used to cover all possibilities of faults using Intelligent Electronic Device (IED). An IED of type SEL $487 \mathrm{~V}$, a switchgear of $13.8 \mathrm{KV}$ voltage level and a fuseless ungrounded double wye SCB of 7 MVAR rating to be used as an example. The following table I, shows the used SCB data.

\begin{tabular}{|c|c|}
\multicolumn{1}{|c}{ TABLE I. Practical field data } \\
\begin{tabular}{|c|c|} 
Parameter & Value \\
\hline SCB MVAR rating & $7.0 \mathrm{MVAR}$ \\
\hline SCB current rating(In) & $293 \mathrm{~A}$ \\
\hline Voltage (Vn) & $13.8 \mathrm{KV}$ \\
\hline Phase CT & $800 / 1$ \\
\hline VT & $13.8 / 0.12$ \\
\hline Neutral CT & $10 / 1$ \\
\hline
\end{tabular}
\end{tabular}

The protection can be classified into current and voltage protections.

\section{A. Current Protection}

There are 8 main current protections: instantaneous overcurrent (50), time delay overcurrent (51), instantaneous earth fault $(50 \mathrm{~N})$, Time delay earth fault $(51 \mathrm{~N})$, neutral unbalance $(60 \mathrm{~N})$, negative sequence (46), undercurrent (37) and circuit breaker failure $(\mathrm{CBF})$.

\section{Instantaneous overcurrent protection (50)}

This protection is aimed to protect the cables between the circuit breaker (CB) and the SCB against short circuit due to LL or L-L-L cable faults or flash overs. The typical current pickup setting is 5 times of the nominal phase current and time setting is $100 \mathrm{msec}$. to avoid any mal-operation due to transient overcurrent during switching as shown in Fig. 16.

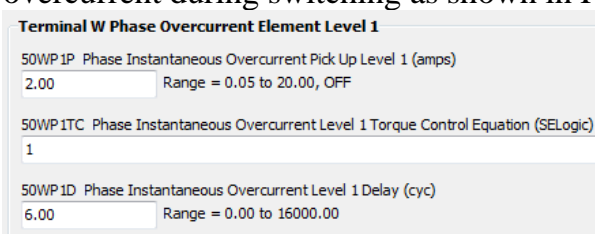

Fig. 16. (50) Protection

$$
\text { In }=\frac{\text { MVAR }}{\sqrt{3} \times V n \times \sin \emptyset}
$$

As per equation (1), In $\cong 293 \mathrm{~A}$. The pickup current Ipu $\cong$ $5 \times 293 \cong 1465 \mathrm{~A}$. Since CT ratio is $800 / 1$, the setting current will be Is $\cong \frac{1465}{800} \cong 2$.
2. Instantaneous earth fault protection $(50 \mathrm{~N})$

This protection is aimed to protect the cables between the circuit breaker (CB) and the SCB against short circuit due to L$\mathrm{G}$ cable faults or flash overs. The typical current pick up setting is 2.5 times the nominal phase current and time setting of 100 msec. to avoid any mal-operation due to transient overcurrent during switching as shown in Fig. 17.

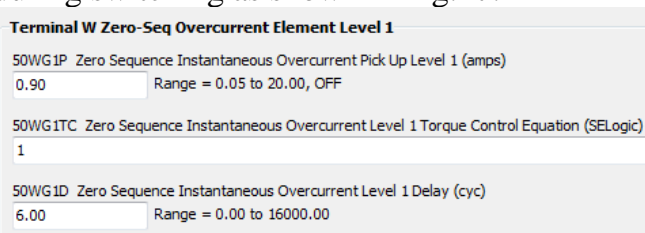

Fig. 17. (50N) Protection

As per equation (1),In $\cong 293$ A. The pickup current Ipu $\cong$ $2.5 \times 293 \cong 733 \mathrm{~A}$. Since CT ratio is $800 / 1$, the setting current will be Is $\cong \frac{733}{800} \cong 0.9$.

3. Time delay overcurrent protection (51)

This protection is aimed to protect the SCB against phase short circuit. The typical current pick up setting is 1.3 times the nominal phase current as shown in Fig. 18.

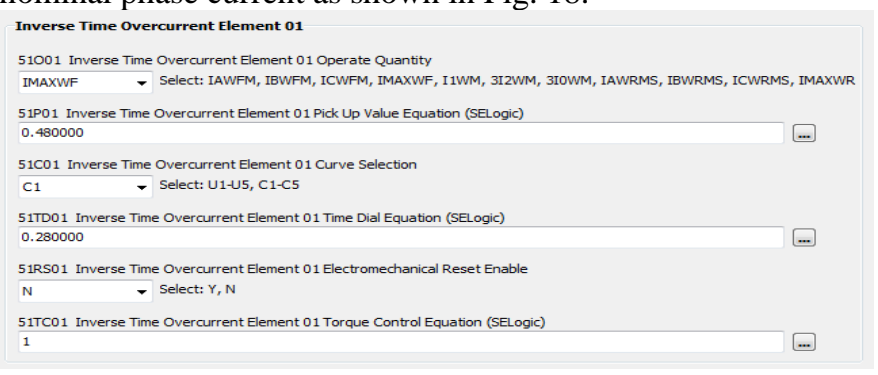

Fig. 18. (51) Protection

As per equation (1),In $\cong 293 \mathrm{~A}$. The pickup current Ipu $\cong$ $1.3 \times 293 \cong 380 \mathrm{~A}$. Since CT ratio is $800 / 1$, the setting current will be Is $\cong \frac{380}{800} \cong 0.48$. Time setting Ts is according to normal inverse curve as per equation (2).

$$
T S=\frac{0.14 \times T p}{(I / I S)^{0.02}-1}
$$

Where, Tp is a time multiplier, I is the actual current.

4. Time delay earth fault protection $(51 \mathrm{~N})$

This protection is aimed to protect the SCB against phase to ground short circuit. The typical current pickup setting is 0.3 times of the nominal phase current as shown in Fig. 19.

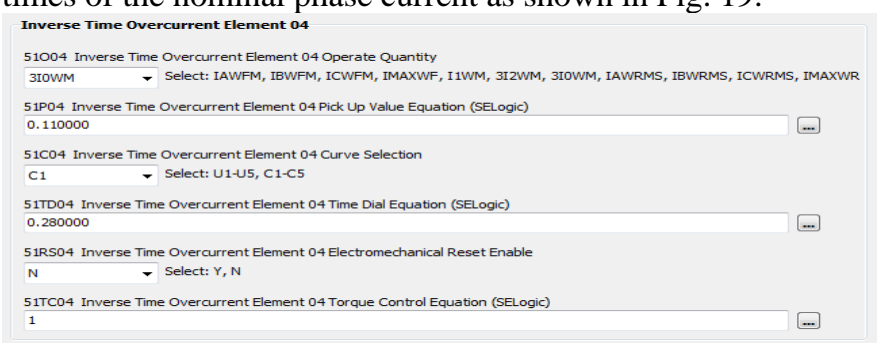

Fig. 19. (51N) Protection

5. Neutral unbalance $(60 \mathrm{~N})$

In the double wye SCB, each phase split into two groups of capacitor units. In case of failure of one or more capacitor units in one group it leads to circulate current from the healthy group to the faulty group. This protection is aimed to detect this 
current through a neutral CT connected between the two group's neutrals and trip the whole SCB as shown in Fig. 20.

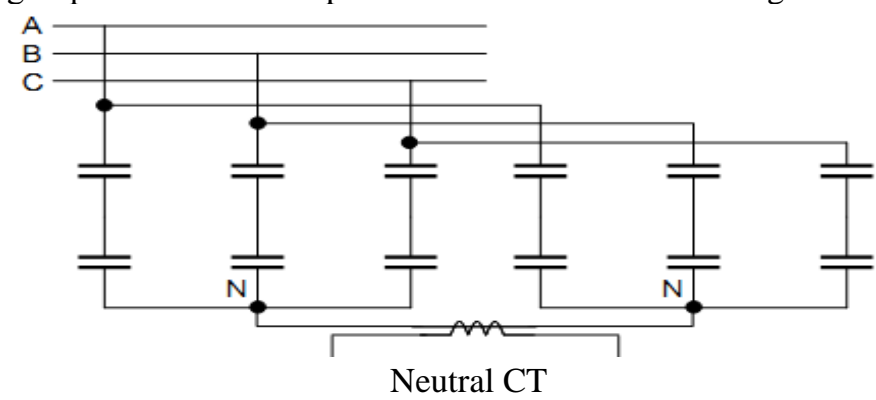

Fig. 20. (60N) Protection connection

Typically there are two stages of neutral unbalance protection. First stage is an alarm if the circulating current value exceeds 3.5 A while second stage is a trip if value exceeded $6.5 \mathrm{~A}$. as shown in Fig. 21.

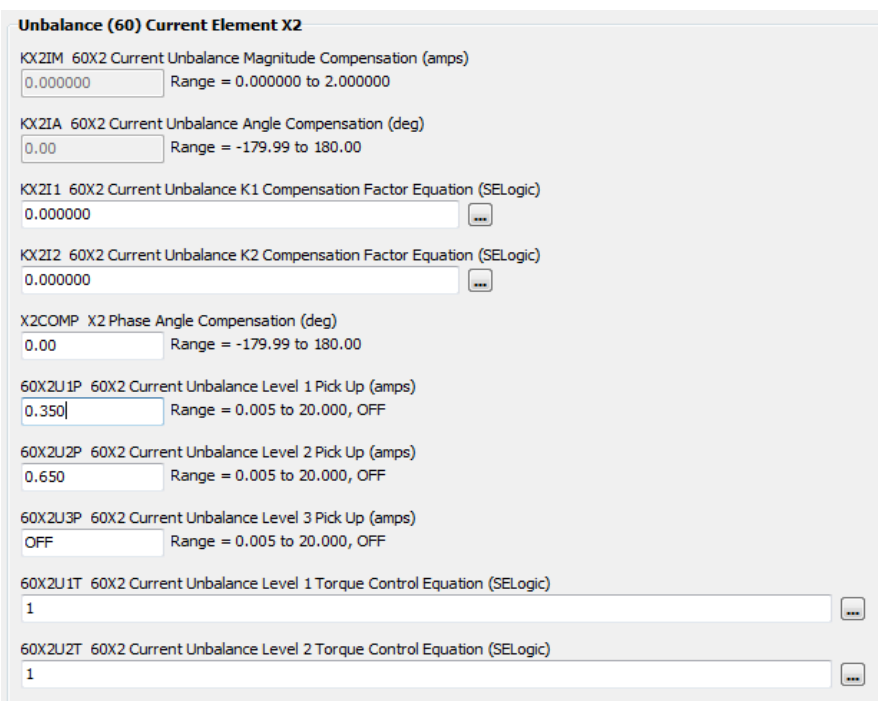

Fig. 21. (60N) Protection

\section{Negative sequence (46)}

This protection is a high sensitivity back up protection to the neutral unbalance protection where it can detect low levels of unbalance current caused by unit failure or unit to unit short circuit as shown in Fig. 22.

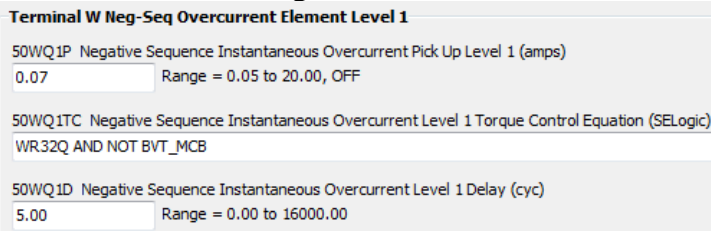

Fig. 22. (46) Protection

This protection should be forward directional to prevent any mal-operation by reverse faults behind bus bars as shown in Fig. 23.

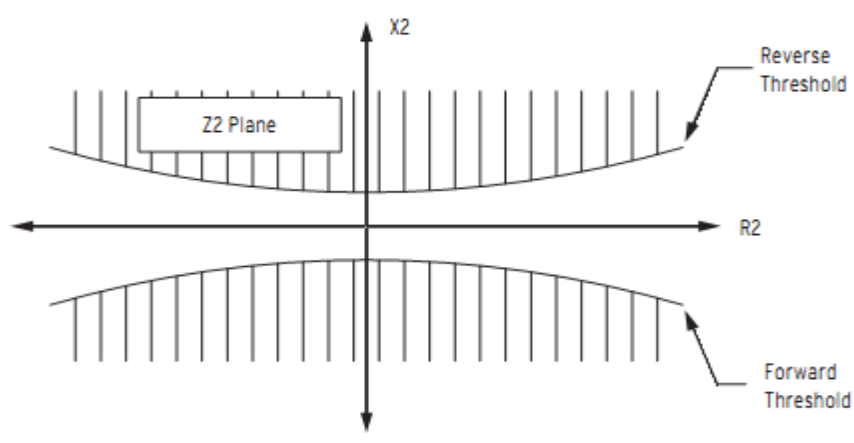

Fig. 23. Negative sequence directional element characteristic

\section{Undercurrent (37)}

It is a simple protection used as an interlock to prevent closing the SCB main CB while the switchgear bus bar is dead. Typical current setting is $50 \%$ of the SCB phase nominal current. This protection also protects against open circuit such as main cable joint removal for any phase.

8. Circuit breaker failure (CBF).

In case of any SCB protection function had operated and the related trip lockout electromechanical relay operated but the main CB was not tripped due to trip circuit faulty, DC system failure or any other reason, the main corresponding $\mathrm{CB}$ supplying the fault must be tripped too. The main inputs of this function are sensing fault current of $10 \%$ of phase CT, trip lockout relay operated as initiation and a time delay of 150 msec. typically as shown in Fig. 24.

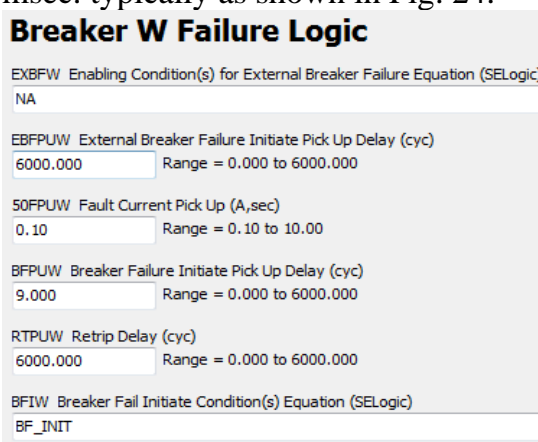

Fig. 24. (CBF) Protection

\section{B. Voltage Protection}

There are 3 main voltage protections: phase overvoltage (59), surge overvoltage and phase under voltage (27).

1. Phase overvoltage (59)

SCB will be subjected to overvoltage due to switching, loss of load and failure of some capacitor units. Phase overvoltage of $110 \%$ of the nominal rated voltage is considered as harmful to the capacitor units' insolation. Typical overvoltage setting is $115 \%$ of the nominal rated voltage and a time delay of $5 \mathrm{sec}$ in order not to operate for switching transient overvoltage as shown in Fig. 25.

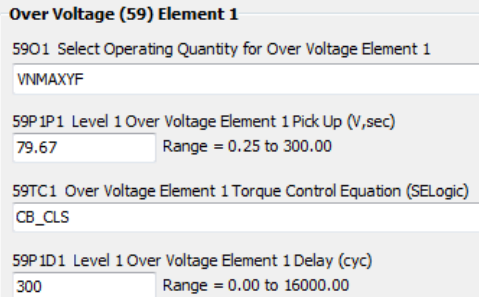

Fig. 25. (59) Protection 


\section{Surge overvoltage}

Since the SCB is outdoor equipment and it is isolated from ground so it is exposed to surge over voltages. A surge arrestor is installed in parallel with the capacitor unit arrangement to provide a safe path to ground as shown in Fig. 26.

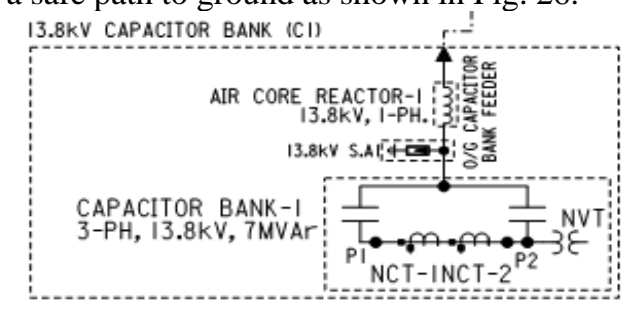

Fig. 26. Surge arrestor position

3. Phase under voltage (27)

Referring to under current protection (37), it is also a simple protection used as an interlock to prevent closing the SCB main $\mathrm{CB}$ while the switchgear bus bar is dead. Typical voltage setting is $70 \%$ of the SCB phase nominal current. This protection also protects against open circuit such as main cable joint removal for any phase.

\section{CONTROL OF DOUBLE WYE UNGRONDED SCB}

SCB main CB and earth switch (ES) must be controlled so that it can provide optimum utilization.

\section{A. SCB main CB switching ON/OFF control}

An SCB located in a three bus bar sectionalized switchgear as shown in Fig. 27, can be controlled using an automatic capacitor control switching system (ACCS) via IED main controller such as ABB REC-670 or SCHNIEDER C264. The controller functions based on voltage and MVAR measurements.

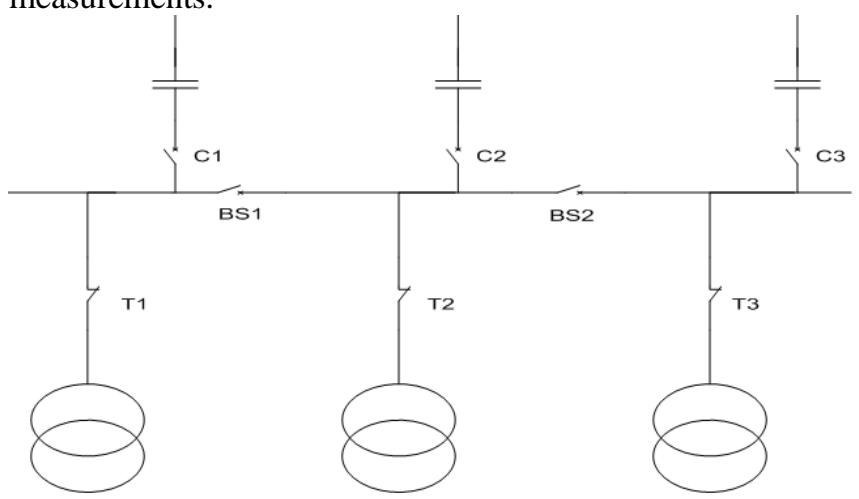

Fig. 27. SCB in 3 sections switchgear

The following points to be considered in the controller logic:

1. MVAR measurements should be from the HV side of the power transformer to cover the overall load MVAR.

2. Voltage measurements should be from bus bar of load center to optimize the required voltage compensation.

3. When incomer transformer $\mathrm{CB}$ in one bus is switched off, the related SCB shall be switched off to avoid overvoltage.

4. Once the SCB CB switched off, it shall not be switched on within 10 minutes to allow the charges to be discharged through the internal resistors.

\section{B. SCB main ES switching ON/OFF control}

ES is a slow motion manually operated switch located in the SCB local control cubicle LCC that used to discharge the trapped charges to ensure a safe working environment with the SCB. The discharge current is limited to $25 \mathrm{KA}$ for only $3 \mathrm{sec}$. Typically SCB has an interlock timer to allow the ES to close only after $10 \mathrm{Min}$. since opening the $\mathrm{CB}$ to protect the ES contact poles and to avoid any arcing that may lead to explosion of the ES as shown in Fig. 28.

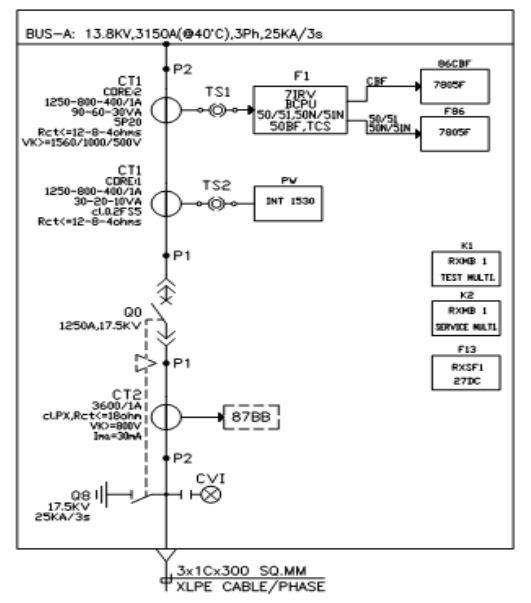

Fig. 28. SLD for SCB LCC

The outdoor SCB is normally surrounded by a fence gate with a special key as shown in Fig. 29. This key has an interlock with the ES so that operators cannot remove the fence gate key for opening the fence gate until the ES is closed for time duration of $10 \mathrm{Min}$.

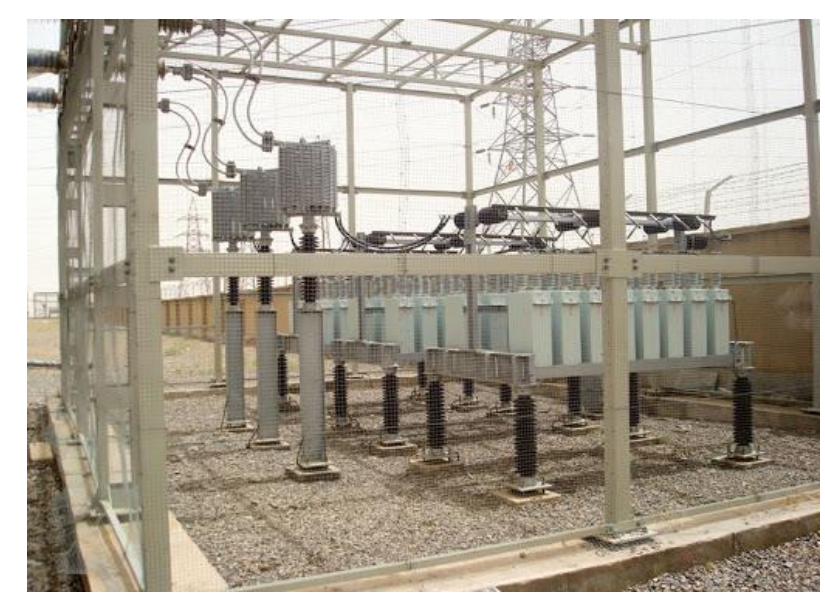

Fig. 29. SCB fence

\section{CONCLUSION}

It has been discussed shunt capacitor bank SCB main types based on arrangement: externally fused, internally fused, unfused and fuseless. Base on grounding: grounded and ungrounded and we went through merits and drawbacks of each type. It has been explored the different protections against all prospective faults either current protections such as instantaneous overcurrent (50), time delay overcurrent (51), instantaneous earth fault $(50 \mathrm{~N})$, Time delay earth fault $(51 \mathrm{~N})$, neutral unbalance $(60 \mathrm{~N})$, negative sequence $(46)$, undercurrent 
(37) and circuit breaker failure (CBF). Voltage protections such as phase overvoltage (59), surge overvoltage and phase under voltage (27). It has been demonstrated briefly the different control methods for SCB CB and ES operations and interlocks.

\section{ACKNOWLEDGMENT}

I would like to pay my special regards to my family especially my parents, my wife and my sons: Moath and Hamza who encouraged me. I would like to thank all people whose assistance was a milestone in the completion of this work. I want to declare that Cairo University is my last academic affiliation where I have been graduated however I don't take any fund from any organization. I would like to link my warm prayers and Duaa to people all over the world supporting fighting CORONA virus (COVID-19).

\section{REFERENCES}

[1] ABB, "Distribution Automation Handbook : Generator Protection," pp. $1-5,2008$.

[2] C. B. Protection, "SEL-487V Relay Capacitor Bank Protection , Automation, and Control Instruction Manual."

[3] B. E. M. C. Publication, P. Fondamentale, and E. N. Cem, "International Standard Internationale," 2009.

[4] S. Samineni, C. Labuschagne, and J. Pope, "Principles of shunt capacitor bank application and protection,” 2010 63rd Annu. Conf. Prot. Relay Eng., no. October 2009, 2010, doi: 10.1109/CPRE.2010.5469505. 